\section{Orthodontic brackets for dental trauma}

Sir, we wish to highlight the recommendations from the Royal College of Surgeons of England regarding the management of dental trauma during the COVID-19 pandemic. ${ }^{1}$ The usage of orthodontic brackets and modules in the management of dental trauma have previously been proven to be effective. ${ }^{2}$ The usage of brackets and wire splints by clinicians may eliminate the need for an AGP as brackets can be removed without the usage of a high speed handpiece. ${ }^{1,2}$

As the capacity of AGPs carried out generally in both primary and secondary care have been greatly reduced, there is also a build-up of patients awaiting treatment in primary care leading to difficulties in accessing primary care. As such, patients often end up in the emergency department (ED) of a hospital, are seen by oral and maxillofacial senior house officers and require follow-up appointments for splint/bracket removal to reduce the risk of ankylosis of the traumatised dentition. With limited access to a clinical assistant and the facilities found in the dental department, it can be a challenging procedure to perform and therefore the competence of the clinician is key.

Whilst such patients commonly present to an ED they may also be readily managed in primary care. For these reasons it may be beneficial for general dental practitioners to attend CPD or refresher courses where appropriate. Ideally, the undergraduate curriculum should also be tailored to ensure this specific clinical skill is being appropriately taught. Students can practise these procedural skills in a suitable facility, as a minimum to ensure confidence and competence upon graduation. With the current surge in COVID-19 and the emergence of a new phase in dentistry, we must ensure the next generation of dentists are well equipped with the change in times.

J. Lee, C. Dale, S. Acharya, A. Shathur, Liverpool, UK

\section{References}

1. Royal College of Surgeons of England. Recommendations for Paediatric Dentistry during COVID-19. 2020. Available at: https://www.rcseng ac.uk/dental-faculties/fds/coronavirus/ (accessed October 2020).

2. Kahler B, Hu J Y, Marriot-Smith C S, Heithersay G S Splinting of teeth following trauma: a review and a new splinting recommendation. Aust Dent J 2016; 61: 59-73.

https://doi.org/10.1038/s41415-020-2514-6

\section{Dental education}

\section{What matters to you?}

Sir, I read with interest Apelian et al.'s recently published article Is the dental profession ready for person-centred care? ${ }^{1}$ Their qualitative study of 11 dentists practising in Quebec Province, Canada found that most of the sample, regardless of their years in practice (3-21 years' service) expressed difficulty with eliciting patient stories, as well as a lack of interest in or an uncomfortableness with the rich narrative data being shared with them. The 'messy' lives of their patients were framed as an 'inconvenience' for dentists who merely wanted to fix their teeth.

These findings confirm the worst about dental education, the persistence of the biomedical approach and the prioritising of technical proficiencies and clinical competencies at the expense of advocating for a model of oral health that is socially determined and where oral care is interactional, dialogical and holistic. While the authors acknowledge the shortcomings of this model and its negative legacy on patientdentist relationships and the profession, they throw down the gauntlet to dental education to rectify this predicament.

Social and behavioural scientists, like myself, working in dental education feel both the responsibility of such a task as well as the impossibility of it. From our interactions with students to timetable schedulers and curriculum designers we encounter individual and institutional resistance in the guise of a 'hidden curriculum' about the behavioural and social sciences as applied to dentistry. ${ }^{2}$ Here in the UK, the GDC acknowledges the role played by the behavioural and social sciences in the undergraduate curriculum. ${ }^{3}$ Nevertheless, we are still waiting for the trickle-down effect to take hold and transform dental education at an institutional level.

In answer to both these dilemmas, 'how can dentists be more patient centred?' and 'how can dental education be more holistic?' - I offer the same four words - 'what matters to you?'

When asked of patients, research confirms that this open question facilitates a dialogue between patient and dentist where mutual respect and understanding about the needs, preferences, expectations and values of each party can emerge and grow. ${ }^{4}$ When asked of dental educators and dental schools, the question 'what matters to you?' forces us to contemplate what is dental education for? Whom does it serve? Where is the patient in all our deliberations? Clarifying our curricular priorities in such a way can help us begin the process of paradigm shift and curricular transformation.

P. Neville, Bristol, UK

\section{References}

1. Apelian N, Verges J-N, Bedos C. Is the dental profession ready for person-centred care? Br Dent J 2020; 229: 133-137.

2. Neville P, Zahra J, Pilch K, Jayawardena D, Waylen A. The behavioural and social sciences as hidden curriculum in UK dental education: a qualitative study. Eur J Dental Educ 2019; 23: 461-470.

3. General Dental Council. Preparing for practice. 2015. Available at: https://www.gdc-uk.org/docs/defaultsource/quality-assurance/preparing-for-practice(revised-2015).pdf (accessed November 2020).

4. What Matters to You. Available at: https://wmty.world/ (accessed November 2020).

https://doi.org/10.1038/s41415-020-2515-5

\section{Endodontics}

\section{Tips for odontogenic infections}

Sir, we write further to the paper on the management of odontogenic infections and sepsis. ${ }^{1}$ We totally agree that early recognition and prompt management of sepsis improves outcomes. As mentioned in the paper, there is a strong belief that once the abscess is formed, surgical drainage is mandatory to achieve resolution. We would like to draw attention to a few additional considerations in managing such situations, which are as follows:

1. Regarding elimination of the source of the infection, if the cause of infection is odontogenic and there is a possibility of saving the tooth, initiation of root canal treatment (RCT) with drainage of the abscess through the canal using copious amount of saline irrigation should be used before incision and drainage is attempted

2. If drainage of the abscess through the root canal is difficult, a sterile \#10 or \#15 K file can be used for slight over instrumentation beyond the apical constriction. This helps in achieving 